\title{
Resistance of T-cells to apoptosis in autoimmune diabetic (NOD) mice is increased early in life and is associated with dysregulated expression of Bcl-x
}

\author{
S.-E. Lamhamedi-Cherradi, J.-J. Luan, L. Eloy, G. Fluteau, J.-F. Bach, H.-J. Garchon \\ INSERM U25 and Institut Necker, Hôpital Necker, Paris, France
}

\begin{abstract}
Summary Activated lymphocytes of autoimmune non-obese diabetic (NOD) mice exhibit an increased resistance to programmed cell death (PCD) following withdrawal of interleukin-2 (IL-2). In the present study, we found that resistance of NOD T lymphocytes to PCD was increased as early as 1 week of age, hence several weeks before the invasion of the pancreas by inflammatory cells, which is compatible with a role of the NOD apoptotic phenotype in the autoimmune susceptibility of this strain. In the thymus, mature single positive but not double positive or double negative thymocytes were more resistant to PCD in NOD compared to B6 mice. Moreover, in both NOD and B6 mice, CD4+ T cells were more re-
\end{abstract}

sistant to PCD induced by IL-2 deprivation than CD8+ cells. As a result, NOD CD4+ T cells were remarkably resistant to cell death induced in this manner. In relation with this increased resistance to apoptosis, expression of the anti-apoptotic $\mathrm{Bcl}-\mathrm{x}$ protein was upregulated in activated T cells of NOD mice, most notably after $24 \mathrm{~h}$ of IL-2 deprivation. These results should help us to understand the relationship of the NOD apoptotic phenotype to the emergence of the NOD mouse autoimmune disease. [Diabetologia (1998) 41: 178-184]

Keywords Apoptosis, ontogeny, T lymphocyte, autoimmunity, diabetes mellitus.
Apoptosis plays an essential role in the homeostasis of the immune system, as demonstrated by the observation of autoimmune symptoms in mouse stains bearing the $l p r$ and gld mutations [1]. These mutations inactivate the Fas (CD95) and Fas-ligand (CD95L) genes, respectively, whose products play an important role in the delivery of apoptotic signals [2, $3]$. Bcl2-transgenic mice have also been shown to develop lupus-like manifestations of autoimmunity [4]. In these models, the causative link between the genetic alteration of apoptosis and the onset or the acceleration of autoimmunity is direct and monogenic,

Corresponding author: Dr. H.-J.Garchon, INSERM U25, Hôpital Necker, 161 rue de Sèvres, F-75743 Paris Cedex 15, France

Abbreviations: NOD, Non-obese diabetic; mAb, monoclonal antibody; IL-2, interleukin-2; PBS, phosphate buffered saline; $\mathrm{PCD}$, programmed cell death; $\mathrm{CBG}$, corticosteroid-binding globulin. although modifyer genes also play a significant role [5].

Most autoimmune diseases, however, are under multifactorial control. Little is known about the apoptotic behaviour of lymphoid cells in common autoimmune diseases. The NOD (non-obese diabetic) mouse strain provides a remarkable model for the study of insulin-dependent diabetes mellitus [6]. Multiple loci influencing disease susceptibility at various stages have now been mapped in the mouse genome [7]. In this context, apoptosis has been shown to be decreased in NOD mouse lymphocytes compared to those from non-autoimmune strains $[8,9]$. The actual contribution of this trait to the autoimmune process now needs to be determined. In the present study, we have further investigated the cellular and molecular basis of this differential apoptotic behaviour of NOD T cells. 
a

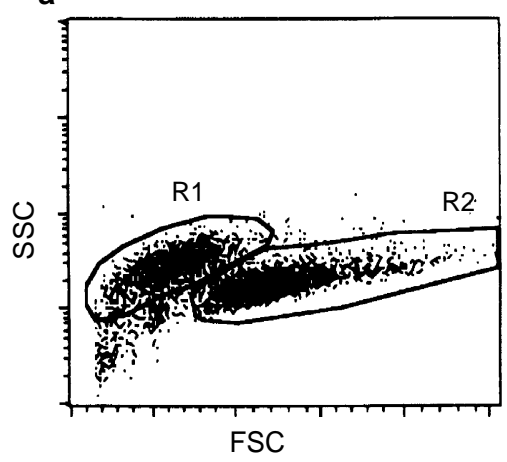

b

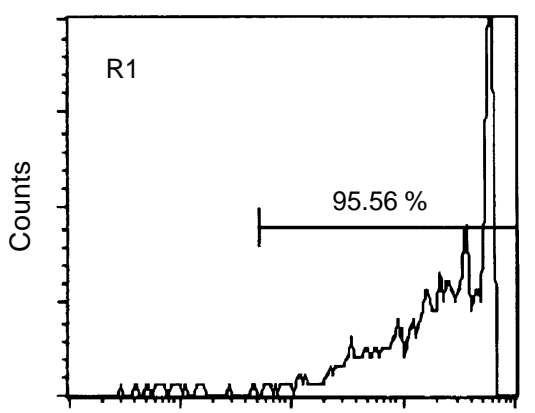

$\mathrm{Pl}$

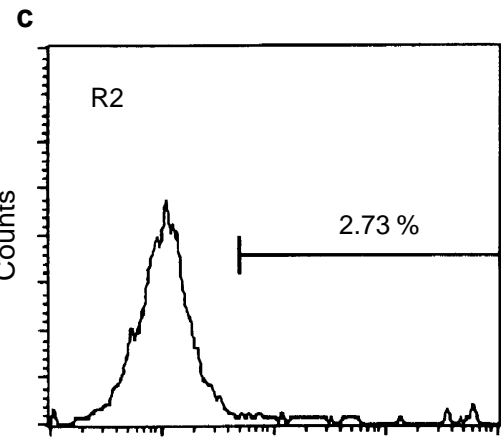

$\mathrm{Pl}$
Fig.1A-C. Correlation of apoptosis evaluation by flow cytometry using the forward and side scatters (A) and by propidium iodide (PI) staining of dead, R1-gated, and live, R2gated, cells ( $\mathbf{B}$ and $\mathbf{C}$, respectively)

\section{Materials and methods}

Mice, antibodies and other reagents. NOD, C57BL/6J, DBA/2, and $\mathrm{BALB} / \mathrm{c}$ mice were bred in our facilities under strict pathogen-free conditions.

The following monoclonal antibodies $(\mathrm{mAb})$ were used: phycoerythrin-conjugated rat anti-L3T4 (YTS191.1; Caltag, San Francisco, Calif., USA), rat anti-CD8 (YTS169.4, Caltag), depleting anti-CD4 (RL172.4 [10]) and anti-CD8 (3.155 [11]), anti-mouse Bcl-x (clone 4; Transduction laboratories, SantaCruz, Calif., USA), anti-mouse tubulin $\alpha$ (Amersham, Slough, UK). Purified human recombinant interleukin-2 (IL-2) (RU49637) was generously provided by Dr. D. Lando (Roussel-UCLAF, Romainville, France).

Induction of apoptosis in splenocytes and thymocytes. Splenocytes were enriched in $\mathrm{T}$ cells by using anti-Ig-coated Petri dishes. In some experiments, enriched $\mathrm{T}$ cells were depleted of CD4 or CD8 cells by treatment with anti-CD8 or antiCD4 mAb and Low-Tox rabbit complement (Cederlane Laboratories, Westbury, N. Y., USA). Dead cells were removed by centrifugation through a Ficoll gradient. Viable cells were polyclonally activated for 3 days in the presence of ConA $(2.5 \mu \mathrm{g} / \mathrm{ml})$ as described previously [8]. Cells were then expanded for 2 additional days in the presence of IL-2. After several washes, cells were resuspended at a concentration of $1 \times 10^{6}$ cells $/ \mathrm{ml}$ in 24 -well culture plates in medium alone (induction of apoptosis by IL-2 deprivation) or in the presence of IL-2.

Freshly harvested thymus cells were directly cultured for $24 \mathrm{~h}$ in RPMI 1640 medium supplemented with $10 \%$ fetal calf serum, $2 \mathrm{mmol} / 1$ glutamine, $50 \mu \mathrm{mol} / 12$-mercaptoethanol. In some experiments, thymus cells were enriched in single positive cells prior to culture by two consecutive treatments with anti-CD4 and anti-CD8 $\mathrm{mAb}$ and rabbit complement.

Apoptotic cells were detected by flow cytometry as described previously $[8,12]$. By comparison with viable cells, they were characterized by a decreased forward scatter and an increased side scatter. These two parameters correlated well with cell death measured by Trypan Blue exclusion [8, 12], or by propidium iodide uptake: the majority of dead cells in the R1 gate were stained with propidium iodide whereas very few live cells in the $\mathrm{R} 2$ gate were PI positive (Fig. 1).
Western blotting detection of $B c l-x$ expression. Cells were lysed as previously described [13]. Protein concentration was determined using the BCA method (Pierce, Rockford, Ill., USA). Fifteen micrograms of protein per sample was migrated on a denaturing SDS- $12 \%$ polyacrylamide gel electrophoresis (SDS-PAGE) [14] and electroblotted onto nitrocellullose membranes. Staining with Ponceau Red confirmed that an equivalent amount of material had been loaded on each lane. Filters were blocked for $1 \mathrm{~h}$ with phosphate buffered saline containing $5 \%$ non-fat milk. All subsequent immunostaining steps and washes were performed in PBSTween 20 at room temperature. Filters were incubated with the primary antibody for $1 \mathrm{~h}$ (anti-Bcl-x, or non-immune mouse $\mathrm{IgG}, 1 \mu \mathrm{g} / \mathrm{ml}$, or anti-tubulin $\alpha$ ). After several washes, biotinylated anti-mouse $\operatorname{IgG}$ rabbit antibodies were added for $30 \mathrm{~min}$, followed by horseradish peroxidase conjugated to streptavidin. Membranes were then incubated with the enhanced chemoluminescence (ECL) detection solution (Amersham) and exposed to X-ray films. To quantitate Bcl-x expression, films were scanned with a densitometer and peak areas for Bcl-x and tubulin- $\alpha$ were determined with the ScanAnalysis software (Biosoft, Cambridge, UK). Normalization ratio between NOD and B6 was obtained by dividing tubulin- $\alpha$ peak area of NOD over B6.

Statistical analysis. Proportions of apoptotic cells in NOD and in B6 strains were compared with Student's $t$-test. The influence of the strain and of the T-cell subset on T-cell death was also evaluated using a logistic regression model. Given the small size of the data set, exact calculations were performed with the LogXact-Turbo program (Cytel Software Corporation, Cambridge, Mass., USA).

\section{Results}

Our initial studies showing an increased resistance of NOD T lymphocytes was performed on splenocytes from adult mice. Enriched T-cells were polyclonally activated for 3 days, further expanded for 2 days in the presence of IL-2, and programmed cell death (PCD) was then induced by withdrawal of IL-2. Investigation of peripheral blood and lymph node $\mathrm{T}$ cells using the same protocol yielded similar results (our unpublished data), indicating that this apoptotic behaviour was a common feature of most NOD peripheral $\mathrm{T}$ cells. Similarly, $\mathrm{T}$ cells from males and females showed no difference in their sensitivity to induction of apoptosis. To understand 

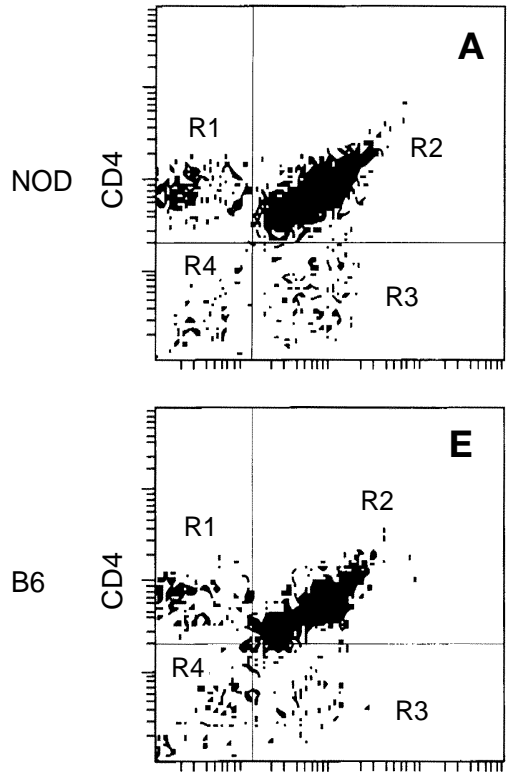

CD8

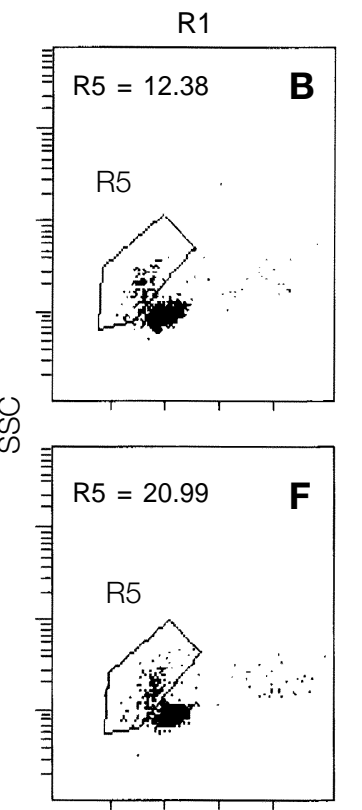

Fig. 2 A-H. Flow cytometric measurement of apoptosis in NOD (A-D) and B6 (E-H) thymocytes. After a 24-h culture period, thymocytes were labelled for CD4 and CD8 surface antigens and analysed by flow cytofluorimetry $(\mathbf{A}, \mathbf{E})$. CD4 single positive $(\mathbf{B}, \mathbf{F})$, double positive $(\mathbf{C}, \mathbf{G})$, and CD8 single positive $(\mathbf{D}, \mathbf{H})$ cells were electronically gated (gates R1-R3, respectively) and assessed for size and density. Apoptotic cells were characterized by a decreased forward scatter (FSC) and an increased side scatter (gate R5) compared to living cells

Table 1. Ontogeny of increased resistance of NOD activated peripheral $\mathrm{T}$ lymphocytes to induction of apoptosis by IL2 deprivation

\begin{tabular}{lrrr}
\hline & \multicolumn{3}{c}{ Cell death $(\%)$} \\
\cline { 2 - 4 } Strain & \multicolumn{1}{c}{ NOD } & \multicolumn{1}{c}{ B6 } & \multicolumn{1}{c}{$p$ value } \\
\hline Age (weeks) & $39 \pm 1.1$ & $56.1 \pm 2.1$ & 0.0005 \\
1 & $36.8 \pm 1.7$ & $52.8 \pm 7$ & 0.0352 \\
2 & $29.8 \pm 0.5$ & $45.1 \pm 0.3$ & $<0.0001$ \\
3 & $37.4 \pm 2.8$ & $54.4 \pm 1.4$ & 0.0017 \\
4 & $30.3 \pm 0.9$ & $57.6 \pm 0.6$ & $<0.0001$ \\
5 & $22.4 \pm 0.4$ & $40.1 \pm 0.3$ & $<0.0001$ \\
6 & $55.1 \pm 3.1$ & $74.1 \pm 3.9$ & 0.0064 \\
7 & $62.3 \pm 4.3$ & $76.7 \pm 5.2$ & 0.0392 \\
11 & $40.9 \pm 2.6$ & $65.3 \pm 1.9$ & 0.0004 \\
20 &
\end{tabular}

Data are mean \pm SD

There were three mice per group.

At 1 week of age, lymph node T cells were tested instead of spleen cells

better the relationship of this feature with the NOD mouse disease, we next sought to characterize its ontogeny; i.e. (i) the time course of its appearance in young mice, and (ii) its relation to thymic differentiation.
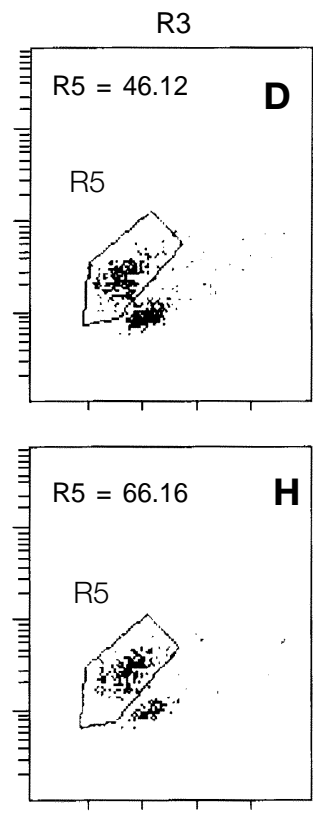

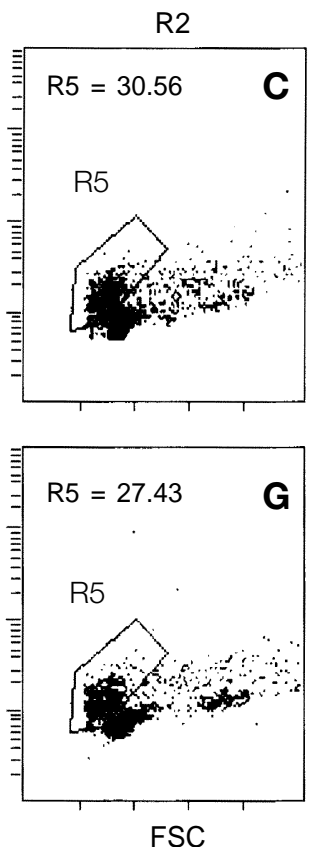

Ontogeny of the resistance of NOD T cells to induction of apoptosis. Analysis at serial time points indicated that the resistance of NOD T lymphocytes to PCD was significantly increased as early as 1 week of age, therefore unambiguously preceding disease onset, and as late as 20 weeks, consistently resulting in a 1.5- to 2-fold increased survival of NOD compared to C57BL/6 (B6) lymphocytes (Table 1).

Apoptosis of NOD and B6 lymphoid cells was then compared in the thymus. To this end, a short-term culture protocol was used. Apoptosis was measured after $24 \mathrm{~h}$ of incubation of adult thymus cells in medium alone, or in medium after addition of dexamethasone, or after initial exposure to ionizing radiations. Cells were then labelled for CD4 and CD8 markers and the number of apoptotic cells was determined by flow cytometry in single positive and in double CD4+CD8+ positive subsets after electronic gating, as shown on Figure 2. Both CD4+ and CD8+ single positive subsets, when incubated in medium alone, were more resistant to PCD in NOD mice (Figs. 2 and 3 ). This differential response between NOD and B6 was also seen after incubation with dexamethasone and exposure to gamma-irradiation but was abrogated by addition of IL-2. In contrast, the death rate of double positive cells tended to be increased in NOD mice. To determine which was the primary phenomenon, the decreased death of single positive thymus cells or the increased death of double positive cells, death of single positive thymus cells was directly evaluated in experiments in which each subset was enriched before culture by treatment with the appropriate antibody against the other subset. Such a treatment eliminated the double positive cells. As shown on Table 2, single positive CD4+ and CD8+ cells died at a lower rate in 


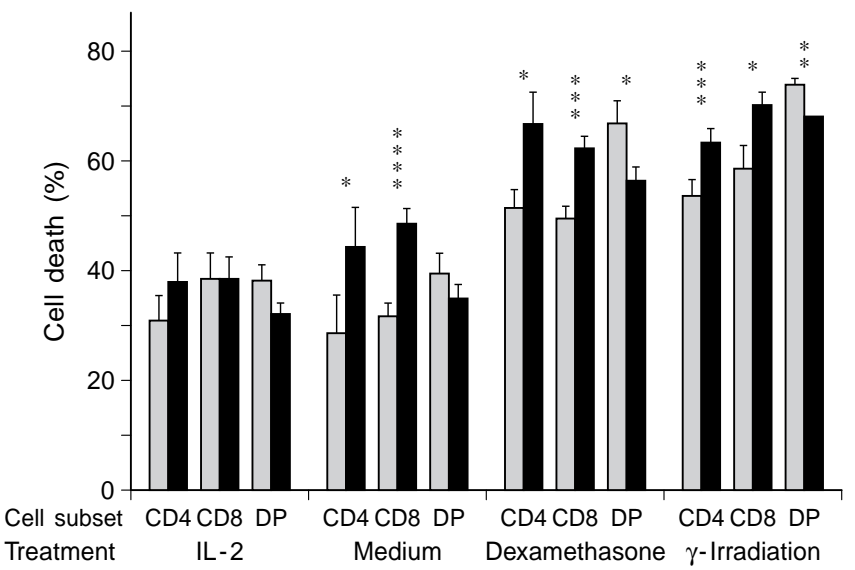

Fig.3. Increased resistance of NOD single positive thymus cells to induction of apoptosis. Thymus cells from NOD ( $\square)$ and B6 mice ( $(3$ mice per group, 6 week-old) were cultured for $24 \mathrm{~h}$ in medium alone, or in the presence of IL2 $(225 \mathrm{U} / \mathrm{ml})$, or dexamethasone $(0.4 \mathrm{nmol} / \mathrm{l})$, or after $\gamma$-irradiation (5 Grays). Cell death was then measured as shown on Figure 2. These results are representative of four separate experiments. ${ }^{*} p<0.05 ;{ }^{* *} p<0.01 ;{ }^{* * * *} p<0.005 ;{ }^{* * * *} p<0.001$

Table 2. Increased resistance of NOD single positive thymocytes to PCD

\begin{tabular}{lllll}
\hline & & \multicolumn{3}{c}{ Apoptotic cells (\%) } \\
\cline { 3 - 5 } & Strain & NOD & B6 & $p$ value \\
\hline Depletion $^{\mathrm{a}}$ & subset & & & \\
anti-CD4 & CD8 & $53.2 \pm 3.1$ & $73.3 \pm 3.3$ & 0.0071 \\
& DN & $44.3 \pm 4.7$ & $53.9 \pm 4.2$ & N.S \\
anti-CD8 & CD4 & $16.4 \pm 2.8$ & $27.1 \pm 1.1$ & 0.0075 \\
& DN & $54.9 \pm 9.8$ & $65.2 \pm 2.3$ & N.S \\
\hline
\end{tabular}

Data are mean \pm SD

There were three mice in each group.

a Thymus cells from 3 week-old mice of the indicated strain were treated with anti-CD4 or anti-CD $8 \mathrm{mAb}$ and rabbit complement. Remaining cells were incubated for $24 \mathrm{~h}$ in medium alone and were assayed for apoptosis by flow cytometry. Gates for the indicated subset were similar to those shown in Figure 2

Table 3. Increased resistance of CD4 spleen T cells to PCD induced by IL-2 deprivation

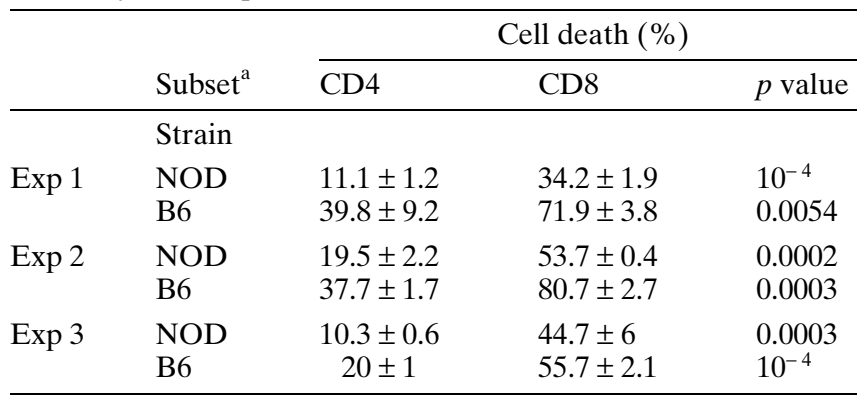

Data are mean \pm SD

There were 3 mice per group

a Enriched T splenocytes from 6 week-old mice were treated with anti-CD4 or anti-CD8 $\mathrm{mAb}$ and rabbit complement, and were polyclonally activated and expanded in the presence of IL-2. Apoptosis was measured after $24 \mathrm{~h}$ of IL-2 deprivation
NOD than in B6 mice whereas PCD of double negative cells was similar in both strains.

Altogether, these data indicate that NOD peripheral $\mathrm{T}$ cells display an increased resistance to PCD early in life and that, in the course of T-cell ontogeny, this apoptotic behaviour can be detected at the stage of single positive thymocytes.

Increased resistance of CD4 T cells to apoptosis. Strikingly, the death rate of CD4 single positive thymus cells was consistently lower than that of CD8 single positive cells, whether in NOD or in B6 mice (Table 2). This difference between the two subsets, which had not been visible using unpurified thymus cells, was confirmed in two other experiments (not shown). However, it was most significant in spleen cells (Table 3). In three separate experiments, CD4+ cells showed dramatically reduced apoptosis compared to CD8+ cells $\left(p<10^{-4}\right.$ by logistic regression analysis, odds ratio $=0.63)$. Again also, NOD $\mathrm{T}$ cells were more resistant to PCD than B6 cells $\left(p<10^{-4}\right.$ by logistic regression analysis, odds ratio $=0.56$ ). Thus, both the T-cell subset (CD4/CD8) and the strain (NOD/B6) strongly influenced IL-2 deprivation-induced apoptosis of T cells. As a result, NOD CD4+ $\mathrm{T}$ cells were remarkably resistant to cell death induced in this manner.

Decreased death rate in NOD T lymphocytes correlates with dysregulation of Bcl-x expression. Proteins of the Bcl-2 superfamily play an essential role in the modulation of lymphoid cell sensitivity to death signals [15]. Among these proteins, Bcl-x protects against PCD induced by a broad array of stimuli [16], notably against PCD induced by IL-2 deprivation in activated T cells [17]. Freshly harvested nonactivated spleen $\mathrm{T}$ cells expressed Bcl-x markedly at 4 weeks of age (Fig. 4A), but at a much lower level at 18 weeks (Fig. 4B), indicating that constitutive expression of $\mathrm{Bcl}-\mathrm{x}$ was dependent on age. This basal expression was not different between NOD and nonautoimmune B6, DBA/2, or BALB/c mice (normalized ratio between NOD and each non-autoimmune strain: $0.9,0.9$, and 1.2 , respectively). In contrast, after activation and IL-2 driven expansion, NOD T cells expressed 1.5-2 fold higher levels of Bcl-x (Fig. 4C-E). This difference was most pronounced, up to 4-fold, $24 \mathrm{~h}$ after induction of apoptosis by IL2 withdrawal. These data indicated that expression of Bcl-x was abnormally regulated following activation in the NOD strain compared to three other nonautoimmune common laboratory strains.

\section{Discussion}

In this work, we have further characterized the cellular basis of the resistance of NOD T cells to induction 

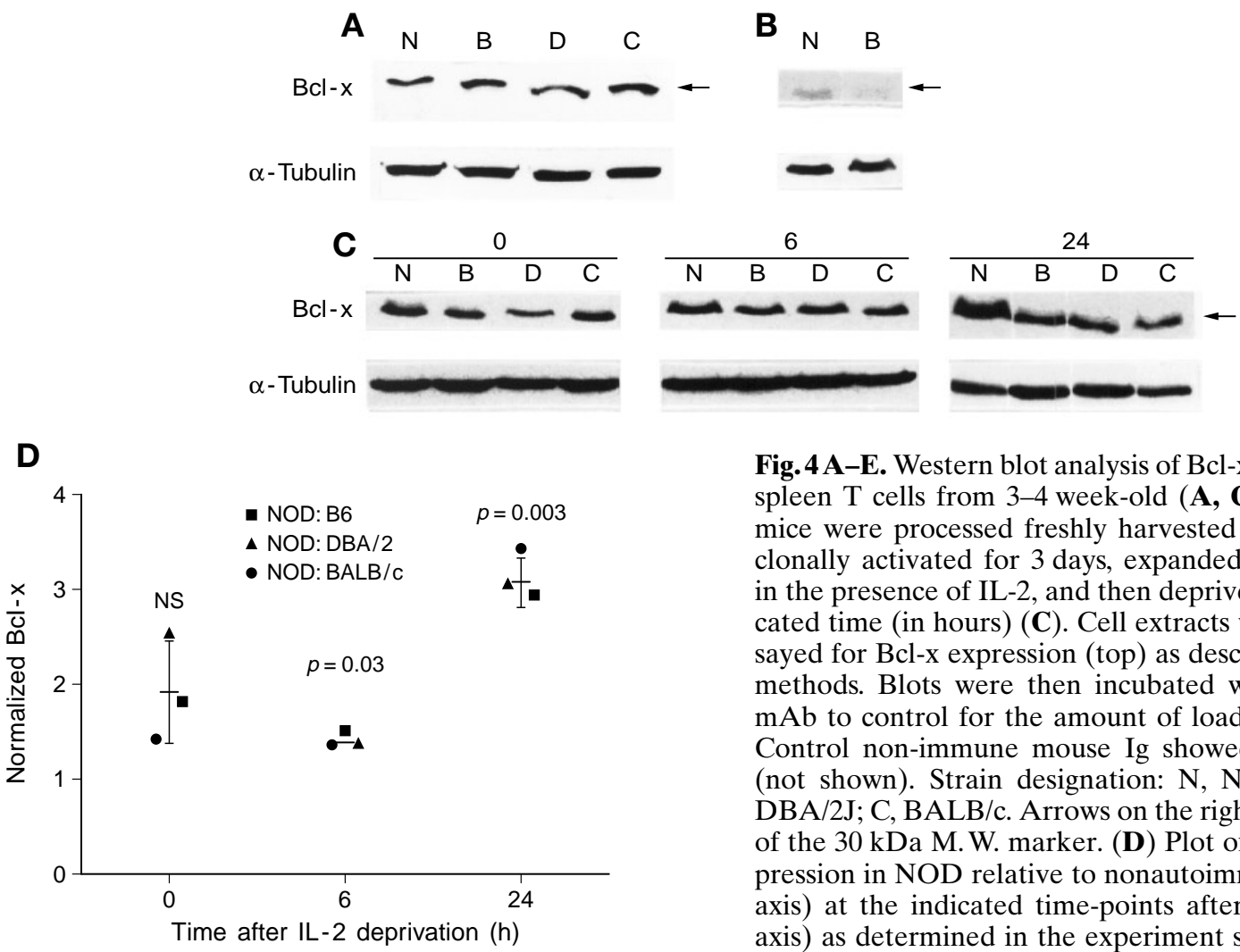

Fig. 4 A-E. Western blot analysis of Bcl-x expression. Enriched spleen T cells from 3-4 week-old (A, C) or 18-week-old (B) mice were processed freshly harvested $(\mathbf{A}, \mathbf{B})$ or were polyclonally activated for 3 days, expanded for 2 additional days in the presence of IL-2, and then deprived of IL-2 for the indicated time (in hours) (C). Cell extracts were prepared and assayed for Bcl-x expression (top) as described in materials and methods. Blots were then incubated with an anti-tubulin $\alpha$ $\mathrm{mAb}$ to control for the amount of loaded proteins (bottom). Control non-immune mouse Ig showed no specific staining (not shown). Strain designation: N, NOD; B, C57BL/6; D, $\mathrm{DBA} / 2 \mathrm{~J} ; \mathrm{C}, \mathrm{BALB} / \mathrm{c}$. Arrows on the right indicate the position of the $30 \mathrm{kDa}$ M.W. marker. (D) Plot of normalized Bcl-x expression in NOD relative to nonautoimmune lymphocytes $(y$ axis) at the indicated time-points after IL-2 deprivation ( $x$ axis) as determined in the experiment shown in (C). (E) Plot of normalized Bcl-x expression in NOD relative to C57BL/6 lymphocytes in four independent experiments, of which one is shown in (C). Expression of Bcl-x was normalized between NOD and each non-autoimmune strain using tubulin- $\alpha$ as a reference. The mean \pm standard deviation of individual values is indicated at each time-point

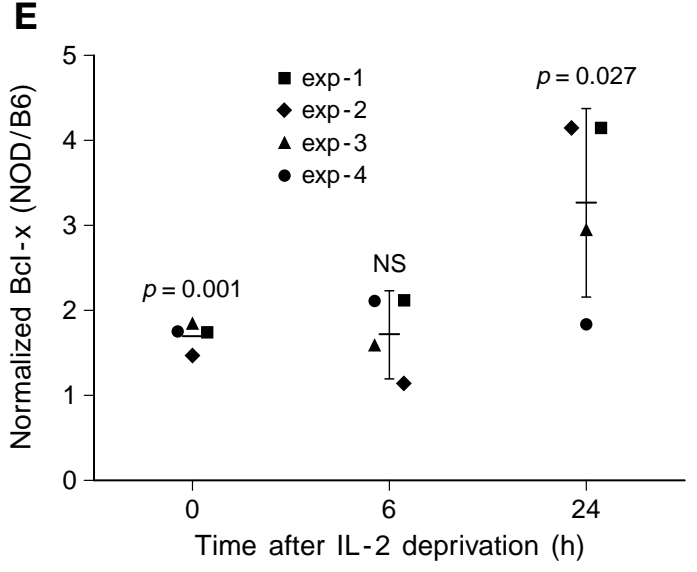

of apoptosis in order to gain insight into the mechanisms underlying this phenotype and its relationship with the autoimmune susceptibility of NOD mice. We focused our study on $\mathrm{T}$ cells taken from outside the inflammatory sites, as our primary purpose was to investigate their intrinsic apoptotic properties prior to any selection bias. Apoptosis of inflammatory cells, notably islet-infiltrating cells, nevertheless deserves a separate study.

Studying the ontogeny of the apoptotic behaviour of NOD T lymphoid cells, we found that, as early as 1 week of age, NOD T cells exhibited an increased resistance to induction of apoptosis when compared to B6 $\mathrm{T}$ cells. We are currently investigating earlier time points, during the fetal and perinatal period. However, as characterized in this study, the differen- tial apoptotic response of NOD T lymphocytes is already the most precocious distinctive immunologic feature described in this strain. It precedes by 2 to 3 weeks the invasion of the pancreas by mononuclear cells $[18,19]$. This inflammatory infiltration proceeds first around the ducts, the vessels and the islets at 34 weeks of age, and represents the earliest manifestation of the NOD mouse disease, several weeks before the onset of insulitis and diabetes.

The earlier increase of the resistance of NOD peripheral $\mathrm{T}$ cells to death suggests that it could contribute to the emergence of autoimmune anomalies. The possible mechanisms by which this could occur are suggested by several studies. In the model of experimental allergic encephalomyelitis, recovery from disease is closely associated with specific elimination by apoptosis of autoreactive $\mathrm{CD} 4^{+} \mathrm{T}$ cells in the central nervous system [20-24]. In mice bearing the ipr mutation, elimination of specific T-cell clones following in vivo neonatal injection of a superantigen is incomplete and of short duration [25]. Finally, in mice bearing a Bcl-2 transgene, the antibody response following antigen stimulation is prolonged [26]. These observations indicate that apoptosis is associated 
with the sedation of an autoimmune response and, conversely, that resistance to apoptosis causes prolongation of an immune response or delays clonal downsizing. Such apoptosis could be induced in particular by the decrease in IL-2 production which occurs at the end of the immune response and results in limited availability of this growth factor. Conceivably, therefore, increased resistance of NOD lymphocytes to PCD induced by growth factor withdrawal could facilitate the survival of emerging autoreactive clones.

Our finding that peripheral $\mathrm{T}$ cells and also single positive mature thymocytes but not double positive thymocytes exhibit an increased resistance to induction of apoptosis is at variance with that of Leijon et al. [9]. However, in their study, apoptosis was induced in vivo by injection of glucocorticoids. Additional factors, notably the pharmacodynamics of the drug, could explain the discrepancy between our two studies. In this regard, in two other models of autoimmunity, the diabetic BB rat and the Obese chicken, a model of Hashimoto's thyroiditis, an altered affinity of corticosteroid-binding globulin (CBG) caused by a point mutation and an elevated level of $\mathrm{CBG}$, respectively, were reported $[27,28]$. Likewise, NOD mice develop an abnormal corticosterone response to a stimulation by IL-1 $\alpha$ [29]. Such alterations of the immune endocrine system could influence autoimmune susceptibility by modulating sensitivity of autoreactive clones to apoptosis independently of their intrinsic resistance to PCD.

The resistance to PCD induced by IL-2 deprivation was greater in CD4+ than in CD8+ $\mathrm{T}$ cells, in both NOD and B6 mice, but it was also more pronounced in NOD mice. In relation to this observation, $\mathrm{CD}^{+}$and $\mathrm{CD} 8^{+}$subsets use distinct PCD pathways, at least following CD3/TCR ligation. In CD4 ${ }^{+}$ $\mathrm{T}$ cells and predominantly in Th1 cells, the T-cell receptor mediates activation-induced death through the Fas-ligand-Fas receptor interaction whereas TNF mediates apoptosis of CD8 cells through the p75 TNF-receptor [30-32]. It will be important to determine whether a subset of NOD CD4 T cells accounts for the increased resistance to death, or $\mathrm{CD} 4^{+} \mathrm{T}$ cells behave homogeneously in response to IL-2 deprivation. In the former, fine characterization of the PCD-resistant subset could provide clues to the pathogenic T-cell subset in NOD mice.

Linkage of periinsulitis and sialitis to the Bcl-2 locus [33] had spurred our analysis of apoptosis in NOD lymphocytes [8]. However, we found no structural or quantitative polymorphism of the Bcl-2 protein to support a role for the Bcl-2 gene itself in the NOD apoptotic phenotype (our unpublished data), which otherwise, is influenced by a locus on chromosome 6 [34]. Our observation of a dysregulated expression of Bcl-x in NOD activated lymphocytes in response to IL-2 withdrawal (Fig.4), is therefore of great interest. Bcl-x and Bcl-2, two potent and closely homologous anti-death factors, exert their action through a common pathway [35], but greatly differ in the regulation of their expression [16, 17, 36-38]. Thus, Bcl-2 is mostly expressed in resting lymphocytes but not in thymus cells and is modestly upregulated following activation. In contrast, Bcl-x is expressed in cortical thymocytes at a high level, is repressed in quiescent cells, and is again induced at a high level following activation, notably through ligation of the CD28 coreceptor and the IL-2 receptor $\gamma$ chain $[39,40]$. Bcl-x is eventually downregulated at the end of the stimulation. In addition, our study revealed that constitutive expression of Bcl-x in lymphoid cells was also subject to an age-dependent regulation. Interestingly, downregulation of Bcl-x was recently reported in male germinal cells at 3-4 weeks of age [41]. Dysregulation of Bcl-x is a good explanation for the increased resistance of NOD activated $\mathrm{T}$ lymphocytes to induction of apoptosis. Whether this dysregulation is a primary anomaly, or is secondary to another still unknown defect, remains to be determined.

In human IDDM, the decreased expression of CD95 at the surface of T lymphocytes might provide an alternative molecular mechanism leading to altered apoptosis [42]. Although there is presently no genetic evidence that the product of the CD95 gene or its ligand contribute to diabetes susceptibility in NOD mice, the CD95-CD95 ligand interaction has been shown to be central to the destruction of beta cells in these mice [43] and perhaps also in humans [44]. In any event, in the same manner as the ipr mutation has been the source of invaluable insight into the mechanisms of cell death, the study of the NOD mouse strain should teach useful lessons on the regulation of PCD in the immune system.

Acknowledgements. We are most grateful to Dr. C. Carnaud for critical reading of the manuscript. This work was supported by funds from INSERM and by grant \# 193131 from the Juvenile Diabetes Foundation.

\section{References}

1. Cohen PL, Eisenberg RA (1991) Lpr and gld - single gene models of systemic autoimmunity and lymphoproliferative disease. Annu Rev Immunol 9: 243-269

2. Watanabe-Fukunaga R, Brannan CI, Copeland NG, Jenkins NA, Nagata S (1992) Lymphoproliferation disorder in mice explained by defects in Fas antigen that mediates apoptosis. Nature 356: 314-317

3. Takahashi T, Tanaka M, Brannan CI et al. (1994) Generalized lymphoproliferative disease in mice, caused by a point mutation in the Fas ligand. Cell 76: 969-976

4. Strasser R, Whittingham S, Vaux DL et al. (1991) Enforced $\mathrm{Bcl} 2$ expression in B-lymphoid cells prolongs antibody responses and elicits autoimmune disease. Proc Natl Acad Sci USA 88: 8661-8665

5. Watson WL, Rao JK, Gilkeson GS et al. (1992) Genetic analysis of MRL-ipr mice - relationship of the Fas apoptosis gene to 
disease manifestations and renal disease-modifying loci. J Exp Med 176: 1645-1656

6. Kikutani H, Makino S (1992) The murine autoimmune diabetes model: NOD and related strains. Adv Immunol 51: 285 322

7. Wicker LS, Todd JA, Peterson LB (1995) Genetic control of autoimmune diabetes in the NOD mouse. Annu Rev Immunol 13: 179-200

8. Garchon HJ, Luan JJ, Eloy L, Bedossa P, Bach JF (1994) Genetic analysis of immune dysfunction in non-obese diabetic (NOD) mice - mapping of a susceptibility locus close to the bcl-2 gene correlates with increased resistance of NOD T cells to apoptosis induction. Eur J Immunol 24: 380-384

9. Leijon K, Hammarstrom B, Holmberg D (1994) Non-obese diabetic (NOD) mice display enhanced immune responses and prolonged survival of lymphoid cells. Intern Immunol 6 : 339-345

10. Sarmiento M, Dialynas DP, Lancki DW et al. (1982) Cloned T lymphocytes and monoclonal antibodies as probes for cell surface molecules active in $\mathrm{T}$ cell-mediated cytolysis. Immunol Rev 68: 135-169

11. Ceredig R, Lowenthal JW, Nabholz M, MacDonald HR (1985) Expression of interleukin-2 receptors as a differentiation marker on intrathymic cell stem cells. Nature 314: 98-100

12. Darzynkiewicz Z, Bruno S, Delbino G et al. (1992) Features of apoptotic cells measured by flow cytometry. Cytometry 13 : 795-808

13. Calenda A, Allenet B, Escalier D, Bach J-F, Garchon H-J (1994) The meiosis-specific Xmr gene product is homologous to the lymphocyte Xir protein and is a component of the XY body. EMBO J 13: 100-109

14. Laemmli UK (1970) Cleavage of structural proteins during the assembly of the head of bacteriophage T4. Nature 227: 680-685

15. Cory S (1995) Regulation of lymphocyte survival by the bcl-2 gene family. Annu Rev Immunol 13: 513-543

16. Boise LH, Gonzalez-Garcia M, Postema CE et al. (1993) $\mathrm{Bcl}-\mathrm{x}$, a bcl-2-related gene that functions as a dominant regulator of apoptotic cell death. Cell 74: 597-608

17. Broome HE, Dargan CM, Krajewski S, Reed JC (1995) Expression of bcl-2, bcl-x, and bax after T cell activation and IL2 withdrawal. J Immunol 155: 2311-2317

18. Castano L, Eisenbarth GS (1990) Type-I diabetes - a chronic autoimmune disease of human, mouse, and rat. Annu Rev Immunol 8: 647-679

19. Miyazaki A, Hanafusa T, Yamada K et al. (1985) Predominance of T-lymphocytes in pancreatic islets and spleen of prediabetic non-obese diabetic (NOD) mice: a longitudinal study. Clin Immunol Immunopathol 60: 622-630

20. Pender MP, McCombe PA, Yoong G, Nguyen KB (1992) Apoptosis of alphabeta $\mathrm{T}$ lymphocytes in the nervous system in experimental autoimmune encephalomyelitis - its possible implications for recovery and acquired tolerance. J Autoimmunity 5: 401-410

21. Reddy S, Liu W, Elliott RB (1993) Distribution of pancreatic macrophages preceding and during early insulitis in young NOD mice. Pancreas 8: 602-608

22. Schmied M, Breitschopf H, Gold R et al. (1993) Apoptosis of T-lymphocytes in experimental autoimmune encephalomyelitis - evidence for programmed cell death as a mechanism to control inflammation in the brain. Am J Pathol 143: 446-452

23. Tabi Z, McCombe PA, Pender MP (1994) Apoptotic elimination of $\mathrm{V}$ beta $8.2(+)$ cells from the central nervous system during recovery from experimental autoimmune encephalomyelitis induced by the passive transfer of $\mathrm{V}$ beta $8.2(+)$ encephalitogenic T cells. Eur J Immunol 24: 2609-2617

24. Tabi Z, McCombe PA, Pender MP (1995) Antigen-specific down-regulation of myelin basic protein-reactive T cells during spontaneous recovery from experimental autoimmune encephalomyelitis: further evidence of apoptotic deletion of auto- reactive $\mathrm{T}$ cells in the central nervous system. Intern Immunol 7: 967-973

25. Zhou T, Bluethmann H, Zhang JJ, Edwards CK, Mountz JD (1992) Defective maintenance of T-cell tolerance to a superantigen in MRL-ipr/ipr mice. J Exp Med 176: 1063-1072

26. Nunez G, Hockenbery D, McDonnell TJ, Sorensen CM, Korsmeyer SJ (1991) Bcl-2 maintains B-cell memory. Nature 353: 71-73

27. Smith CL, Hammond GL (1991) An amino acid substitution in Biobreeding rat corticosteroid binding globulin results in reduced steroid binding affinity. J Biol Chem 266: 18555-18559

28. Wick G, Hu YH, Gruber J (1992) The role of the immunoendocrine interaction via the hypothalamo - pituitary adrenal axis in autoimmune disease - emphasis on the obese strain chicken model. Trends Endocrinol Metab 3: 141-146

29. Amrani A, Jafarian-Tehrani M, Mormede P et al. (1996) Interleukin-1 effect on glycemia in the non-obese diabetic mouse at the prediabetic stage. J Endocrinol 148: 139-148

30. Zheng LX, Fisher G, Miller RE, Peschon J, Lynch DH, Lenardo MJ (1995) Induction of apoptosis in mature T cells by tumour necrosis factor. Nature 377: 348-351

31. Ramsdell F, Seaman MS, Miller RE, Picha KS, Kennedy MK, Lynch DH (1994) Differential ability of Th1 and Th2 T cells to express Fas ligand and to undergo activation-induced cell death. Int Immunol 6: 1545-1553

32. Suda T, Okazaki T, Naito Y et al. (1995) Expression of the Fas ligand in cells of T cell lineage. J Immunol 154: 3806-3813

33. Garchon HJ, Bedossa P, Eloy L, Bach JF (1991) Identification and mapping to chromosome-1 of a susceptibility locus for periinsulitis in non-obese diabetic mice. Nature 353: 260-262

34. Penha-Goncalves C, Leijon K, Persson L, Holmberg D (1995) Type 1 diabetes and the control of dexamethazone-induced apoptosis in mice maps to the same region on chromosome 6 . Genomics 28: 398-404

35. Chao DT, Linette GP, Boise LH, White LS, Thompson CB, Korsmeyer SJ (1995) Bcl-X(L) and bcl-2 repress a common pathway of cell death. J Exp Med 182: 821-828

36. Veis DJ, Sentman CL, Bach EA, Korsmeyer SJ (1993) Expression of the Bcl-2 protein in murine and human thymocytes and in peripheral T lymphocytes. J Immunol 151: 2546-2554

37. Krajewski S, Krajewska M, Shabaik A et al. (1994) Immunohistochemical analysis of in vivo patterns of Bcl-X expression. Cancer Res 54: 5501-5507

38. Merino R, Ding L, Veis DJ, Korsmeyer SJ, Nunez G (1994) Developmental regulation of the $\mathrm{Bcl}-2$ protein and susceptibility to cell death in B lymphocytes. EMBO J 13: 683-691

39. Boise LH, Minn AJ, Noel PJ et al. (1995) CD28 costimulation can promote $\mathrm{T}$ cell survival by enhancing the expression of Bcl-x(L). Immunity 3: 87-98

40. Akbar AN, Borthwick NJ, Wickremasinghe RG et al. (1996) Interleukin-2 receptor common gamma-chain signaling cytokines regulate activated $\mathrm{T}$ cell apoptosis in response to growth factor withdrawal: selective induction of anti-apoptotic (bcl-2, bcl-x(L)) but not pro-apoptotic (bax, bcl-x(S)) gene expression. Eur J Immunol 26: 294-299

41. Rodriguez I, Ody C, Araki K, Garcia I, Vassali P (1997) An early and massive wave of germinal cell apoptosis is required for the development of functional spermatogenesis. EMBO J 16: 2262-2270

42. Giordano C, De Maria R, Stassi G et al. (1995) Defective expression of the apoptosis-inducing CD95 (FAS/Apo-1) molecule on T and B cells in IDDM. Diabetologia 38: 1449-1454

43. Chervonsky AV, Wang Y, Wong FS et al. (1997) The role of FAS in autoimmune diabetes. Cell 89: 17-24

44. Stassi G, Todaro M, Richiusa P et al. (1995) Expression of apoptosis-inducing CD95 (FAS/Apo-1) on human $\beta$-cells sorted by flow cytometry and cultured in vitro. Transplant Proc 27: 3271-3275 